\title{
Editorial: Canadian Association on Gerontology Policy Statement on Issues in the Delivery of Mental Health Services to Older Adults
}

\section{Introduction}

Elderly people with mental health problems are a particularly vulnerable population with unique health care needs. Health care systems are being reorganized in an effort to ensure that resources are allocated efficiently and used effectively. Data collection, program evaluation and quality assurance have become important activities central to health care reform. In this time of reorganization, it is important that the special needs of vulnerable populations not be overlooked and the principles of care be clearly articulated.

It is our intention to present an overview of the needs of older adults with mental health problems and evidence based strategies to meet them, to facilitate the development of rational policy and program decisions that lead to effective and humane care. Issues relevant to the delivery of mental health services to older adults will be examined, but it should be noted that it is beyond the scope of this document to provide a comprehensive review of all programs delivering mental health services to older Canadians. Instead, the goal of this paper is to encourage a shift in practice toward a clearer realization of the principles of appropriate care for older persons with mental health problems. Much of the research available on issues concerning the mental health of older adults has not, as yet, been meaningfully incorporated into practice. Moreover, how people with mental health problems or disorders and their families view the services they receive can be very informative and assist in ensuring accessible, relevant service delivery. Information, education and training are central to ensuring delivery of appropriate services.

We begin by providing background information about the problem and principles of care, followed by discussion of the need for specialized mental health services for elderly people. We acknowledge our strong belief that a social model of care, incorporating an understanding of the impact of psychological, social, physical and environmental factors on mental health, is the most appropriate model of care for elderly persons with mental health problems. In the following section, we provide an overview of principles of appropriate care of elderly persons with mental health problems. We then address the application of these guiding principles to the delivery of mental health services to older people with mental health problems.

\section{Background}

Approximately 12 per cent of the Canadian population is 65 years and older. The Canadian Medical Association (1987) states that at any given moment, approximately 30 per cent of Canadian seniors require mental health services. Similarly, Health and Welfare Canada (1991) places the prevalence rate at 25 per cent. Gurland and Cross (1982) suggest that 15-20 per cent of elderly persons may be in need of psychiatric services. Blazer and Maddox (1982) reported that 5-10 per cent of seniors in the community suffer from severe psychiatric impairment and another $10-40$ per cent suffer from mild to moderate impairment.

Beginning in the early 1980's, the elderly population became the focus of increased attention from provincial and federal levels of government, health care institutions, community agencies, and universities, as evidenced by the growing number of interest groups, conferences, grants, publications and task forces in the field (Béland, 1997). Concurrently, concern for the mental health of older persons was expressed by Health and Welfare Canada in a number of publications (e.g., 1991, 1990, 1988a, 1988b). These federal initiatives strongly influenced the development of guidelines and planning frameworks at provincial levels. In many jurisdictions, responsibility for health care (including mental health services) is now being transferred to regional health authorities. It has been argued that having one administrative system, such as a regional health authority, may provide solutions to some of the difficulties experienced in complex multi-faceted health systems (Shulman, 1991). However, this can only be realized if the new authorities are aware of the existing models of mental health service delivery, the principles on which they are based, and the limitations of how the models are applied in practice. The World Health Organization \& World Psychiatric Association have together recently published a technical consensus statement on the organization of care for elderly persons with mental disorders that provides guidance to those developing policy and programs in this area (World Health Organization and World Psychiatric Association, 1998). The British Columbia Psychogeriatric Association, a multi-disciplinary organization of profession- 
als working in the field of psychogeriatrics, has developed a set of principles of psychogeriatric care (British Columbia Psychogeriatric Association, 1999). These principles for services to older adults with mental health problems and their families are meant to guide the planning and development of health care services for elderly persons with mental health problems. According to these principles, these services are viewed as goal-oriented, flexible, comprehensive, client-centred, accountable, and specific to the needs of older adults.

\section{Specialized Mental Health Services for Older Persons}

Mental health, as conceptualized by consumers, families, and mental health professionals and defined in Mental Health for Canadians: Striking a Balance (Health and Welfare Canada, 1988b) is:

\begin{abstract}
the capacity of the individual, the group and the environment to interact with one another in ways that promote subjective well-being, the optimal development and use of mental abilities (cognitive, affective and relational), the achievement of individual and collective goals consistent with justice and the attainment and preservation of conditions of fundamental equality (p.7).
\end{abstract}

A mental health problem is defined as a disruption in the interactions between the individual, the group, and the environment and may result from factors associated with the individual (e.g., physical or mental illness, inadequate coping skills), or from external causes (e.g., environmental conditions, social structures or relationship dynamics) (Health and Welfare Canada, 1988b). Conversely, a mental disorder is defined more narrowly as "a medically diagnosable illness that results in significant impairment of an individual's cognitive, affective or relational abilities" (Health and Welfare Canada, 1988b, p.8). However, even in the face of severe mental disorder, the disorder is not the only determinant of mental health. Mental health disorders coexist with mental health problems that must also be addressed if optimal mental health is to be achieved (Health and Welfare Canada, 1988b).

The need for specialized mental health services for elderly people has been well documented in the literature, focussing on three main areas: (1) age-related differences in presentation, (2) barriers to receiving care, (3) age-related developmental and social factors. Until fairly recently, there was virtually no recognition that the mental health problems of elderly persons differed from those of other adults.

\section{Age-Related Differences in Presentation}

Depression, dementia, delusional disorders, and delirium are the most common mental health disorders among elderly persons. Although these disorders may also be experienced by younger adults, there are age-related differences. Dementia and delirium, for example, present much more frequently in older adults than in younger adults. Depression and delusional disorders may present quite differently in older adults as compared to younger adults.

Dementia is age-associated, affecting less than 1 per cent of persons under age 65 as compared to 35 per cent of individuals over 85 (Canadian Study of Health and Aging Working Group, 1994). As such, it is one of the most important conditions for health care professionals, service providers, and policy makers to understand. Dementia sufferers require various levels and types of care, depending on the stage of the disorder and the presenting symptomatology (e.g., affective or psychotic features, behaviour problems). Providing care is a major challenge for family and staff. Care providers require much assistance and support (e.g., educational, physical, and mental health related). The complexity of the dementia syndromes and their impact on others demand a broad range of knowledge and skills to assess the complex array of biological, psychological, social, and environmental factors that affect the provision of optimal care and to assist in the effective management of problems in whatever setting they occur.

Delirium (i.e. fluctuations in consciousness, attention, and orientation) has been described as the most common and potentially reversible lethal mental health disorder of old age (Beresin, 1988). Although delirium is considered a medical emergency, it is poorly recognized as such, even in acute care settings. Many conditions that would be relatively innocuous in a younger, healthier person (e.g., infections of any sort, urinary retention, constipation, faecal impaction) can result in a delirium in elderly persons. Precipitants to delirium include: pre-existing cognitive impairment, age-related changes in pharmacokinetic and pharmacodynamics of drugs, reduced resistance to acute diseases, severity of chronic diseases, sleep loss, sensory deprivation, sensory overload, impairment of vision and hearing, psychosocial stress, bereavement, or relocation to an unfamiliar environment (Lipowski, 1989). Elderly persons take more prescription medications than younger people. This places them at greater risk of harmful drug interactions, as well as adverse effects from individual medications, which can cause a delirium (Lee, 1996). Early detection and prevention of delirium requires specialized knowledge about these predisposing factors and how to manage them if unnecessary hospitalizations and/or death are to be 
avoided. The education of health care providers in the recognition and management of delirium is of major importance.

Accurate detection of depression in older persons can be complicated by many factors specifically related to age. Symptoms such as sadness, withdrawal, reduced energy, listlessness, and increased fatigue may be viewed simply as symptoms of aging (Wasylenki, Martin, Lennox, Perry, \& Harrison, 1987). A range of predictors for depression in elderly people has been identified: physiological changes in aging; multiple losses; the presence of chronic disease; reduced social status, social and economic resources, and mastery (Clark \& Vorst, 1994; Badger, 1993). Some physical illnesses more commonly found in older people, and the medications to treat them, can cause depression (Spar \& La Rue, 1990; McCullough, 1991). Due at least in part to these factors, missed diagnoses, mis-diagnoses, and over-diagnoses may all occur with potentially lethal consequences. Males aged 76 and older have the highest rate of suicide in nearly all industrialized countries (Pearson \& Conwell, 1995). The treatment of depression is multi-faceted; when a clinical depression is diagnosed, various interventions may be required depending on the situation (e.g., emotional support, augmentation of the support system, psychotherapy, medication, treatment of physical disorders, and electro-convulsive therapy), utilizing the skills of a number of disciplines. Mossey, Knott, Higgins, and Talerico (1996) found an association between depression in elderly persons and physical and social disability, and that psychosocial interventions were effective treatment strategies in these instances. It is imperative that more resources be put into the prevention and early detection and treatment of depression, and into psychosocial rehabilitation.

Delusional disorders or psychoses in elderly persons (characterized by delusions, hallucinations, thought disorder, bizarre behaviour, or other evidence of loss of touch with reality), can be disorders in their own right or a manifestation of other disorders such as dementia, delirium, or depression (Jeste, Harris, \& Paulsen, 1996). Determining the underlying causes for and factors contributing to late-life delusional disorders, both physical and social, is complex and requires the skills of a number of disciplines, as does their management. Delusions of theft or of infidelity are often associated with dementia and can cause considerable stress to family caregivers (Rockwell, Jackson, \& Vilke, 1994). Hallucinations or delusions may accompany delirium, and it is possible that in successfully treating the psychiatric symptoms, the underlying cause of the delirium may be overlooked. Classical delusions, which may be a continuation of a previous psychosis or of late onset, require similar treatment to those of younger adults, with age-appropriate adjustment of medication. Some individuals may refuse medical treatment for their delusions, or treatment may not be effective (Tuokko, Frerichs, Halpern, \& Eisner, 1999). In these instances, the major emphasis is on working with the clients' social support network to increase others' understanding and tolerance of their behaviour and to stabilize the support system to enable them to remain in as familiar an environment as possible.

\section{Barriers to Receiving Care}

Barriers deterring older persons from using traditional adult community mental health services have been both system-centred and client-centred (Zarit, 1980; German, Shapiro, \& Skinner, 1985). Our culture's negative attitude toward elderly persons may be reflected by many mental health specialists (Paterson, 1976; Butler, 1975). The problem of accessibility to services is of particular concern for older persons who may be physically unable to leave home or the longterm care facility which is now their home (Knight, 1994). Low utilization of community mental health centres by elderly persons has also been linked to the stigma of "mental illness" assigned by the current cohort of elderly persons who associate mental disorder with personal failure or spiritual deficiency (Lebowitz, 1988). In Canada, steps have been taken to address at least some of these barriers with the development of outreach programs in geriatric mental health (Stolee, LeClair, \& Kessler, 1994; Wargon and Shulman, 1987).

The care of the majority of older persons with mental health problems can be managed at home with supports or in residential care facilities. However, a significant number of elderly people may have multiple problems that make it difficult to meet their care needs. For example, as the chronically mentally ill population (e.g., manic-depressive, schizophrenic) ages, some will also develop physical or psychiatric complications of aging. More people with mental handicaps are living longer and, in particular, those with Down's Syndrome, who are at particular risk for developing Alzheimer's-like dementia, may require home or residential services (Janicki \& Dalton, 1999). There are some people with dementia or other psychiatric disorders who have unpredictable aggressive outbursts that can not be consistently managed and, therefore, pose significant care problems. A personality disorder, for example, may be overlaid by one or more complicating factors: deteriorating physical status; social or medical crises; alcohol abuse; socially inappropriate behaviour; antisocial or psychotic behaviour; physical aggression. Elderly individuals from minority groups with specific cultural and language needs who also suffer with mental health prob- 
lems may experience difficulties in the mainstream health care system.

Each of the aforementioned populations has special needs that may not be met by generic services provided to elderly persons (i.e. long-term care facilities or home support) or by adult mental health services. The provision of care to these populations will require educating care providers in a variety of settings (e.g., medical services, long-term care facilities, drug and alcohol services, multicultural programs) about mental health issues. Some of these providers may be unfamiliar with the needs of the psychogeriatric population or apprehensive of becoming involved when the client has a mental health problem. In addition, those already working with the psychogeriatric population will require education about the specific needs of special populations. Collaboration in assessment and care will have to occur between service systems, perhaps with case management shifting from one service to another as needs are redefined. Specialized resources (e.g., day programs, Special Care Units, inpatient psychogeriatric assessment and treatment units, tertiary care facilities) and approaches may need to be developed or expanded to meet the needs of these populations if they are to be integrated into the general service stream for elderly persons. Strategies are also needed for bringing agencies together over client-centred issues (e.g., reporting elder abuse, common clients) with an aim of finding ways to access the most appropriate services.

\section{Developmental and Social Factors}

It is important that those working with older persons be aware of changes associated with normal aging so that they do not confuse them with pathology. Older persons suffer from more chronic diseases and degenerative disease processes than younger adults (Statistics Canada, 1990). These may produce a variety of symptoms (e.g., discomfort, loss of stamina, vigour, and mobility) to which adaptations must be made.

In response to the higher prevalence of disorders, older persons use more medications than young adults. Physiological changes related to aging affect absorption, distribution, detoxification, and excretion of drugs (Martin, 1987) and result in an increased vulnerability to side effects. These physiological changes may result in disabilities that may limit older persons' abilities to carry out former activities of daily living. This may have an impact on their abilities to socialize in the community or remain at home. Removing or reducing offending medications may result in marked improvements. A knowledge of medications most commonly taken by elderly persons and of the idiosyncratic effect these medications, singly or in combi- nation, may have on the elderly person is imperative for health care providers working with older people.

Losses, social isolation, and loneliness can predispose elderly people to mental health problems. Spouses, friends, and siblings may be lost to death, debilitating diseases, physical impairments, and/or cognitive dysfunction. It may be possible to prevent mental health consequences from occurring by creating opportunities for elderly people to effectively cope with losses and to fill the "gaps" left by them. Thus, important tasks for those working with elderly people are to help them to navigate losses and transitions when these jeopardize their mental health; to reconnect them to their social network or develop a prosthetic social network; and to provide education about the social losses associated with aging and the impact the cumulative effects of these may have on the client's morale.

\section{From Theory to Practice}

The adoption of the Guidelines (Health and Welfare Canada, 1988a) and a broad definition of mental health as keystones in planning services to meet the mental health needs of elderly people arose in concert with efforts to redefine health care and shift its focus from institutions to the community. We might expect, with this convergence in thinking, that a new order would arise and a model system would develop to meet the mental health needs of elderly people.

The current health care system has not yet realized the aims for meeting the mental health needs of older persons as described in the Guidelines for various reasons. Three explanations for this failure are apparent:

1. the continued reliance on medical diagnosis as an outcome;

2. the over-riding emphasis on health care costs;

3. the present continuum of formal community services was never designed for elderly persons with mental health problems, and their needs cannot always be met by the services available to them.

\section{Medical Focus}

A continued emphasis on medical diagnosis as an outcome in mental health programs limits the services provided and shapes the team's structure, thinking, and problem-solving strategies. McCubbin (1994) contends that the team and case management models of professional intervention have become hierarchical structures, controlled by psychiatrists or conceptualized by them. The power of psychiatry is supported by a system that, as discussed, monitors mental health programs primarily by counting psychiatric diagnoses. Kenny (1996) stated that the multidisciplinary team as an egalitarian group with equal voice is 
largely a myth. She argues that the language of case discussions and of the case record reflects a strongly medical perspective, with other disciplines adapting their language and perspectives accordingly in order to increase their credibility. The perspectives of nonmedical disciplines are thus muted, to the detriment of elderly persons with mental health problems and their families.

Teams, as small groups, are subject to group dynamics, which in turn affect team functioning. There is some literature (Butterill, O'Hanlon, \& Book,1992) on the importance of attention to team dynamics in ensuring healthy functional teams, but, in practice, programs do not have time allocated to team development (MacCourt, 1993). As a consequence, a hierarchical model, with medicine at the top, tends to dominate, which is in conflict with the values, purposes, and functioning of the social model of care most appropriate for older persons with mental health problems (Knight \& Kaskie, 1995; Health and Welfare Canada, 1988a; Blazer \& Maddox, 1982).

The premise on which the effectiveness and efficacy of the team approach in health care is based is the idea that the knowledge, skills, and problem-solving ability of the group will be more powerful than the sum of its individual parts. This premise is only true when each person is as respected and as valued as each other team member and when function, relationships, and power on the team reflects this. Moreover, unless team functioning is explicitly fostered, the resulting dysfunctional team can negatively affect the ability of the team to work together on common goals. The growth and development of healthy multi-disciplinary teams must be fostered. Ongoing education and resources for the team are necessary, as are ways to identify and address dysfunctional team dynamics when they occur.

In addition to affecting team function, the focus on psychiatric diagnoses as program outcome limits the support for non-medical or non-pharmaceutical interventions, in spite of evidence of their effectiveness. Mittelman et al. (1993) have demonstrated that a comprehensive counselling program for spouse-caregivers can delay institutionalization of Alzheimer's disease patients. Carstensen and Fremouw (1981) demonstrated that a behavioural clinical approach can be an effective intervention in the management of late life paranoia. Macaskill (1987) reported the successful non-pharmacological treatment of a delusional parastosis. Chadwick and Lowe (1994) reported the effectiveness of cognitive therapy in modifying delusions. There is evidence to indicate that psychotherapy can be as effective as medication in treating elderly outpatients with symptoms of depression. For example, Scogin and McElreath (1994), in a quantitative over- view of psychotherapy studies, identified 17 intervention studies in which the magnitude of effect for psychotherapy, generally compared to no treatment, was similar to that of medication compared with placebo in other studies. In Australia, Rosewarne, Bruce and McKenna (1997) demonstrated how facility consultation and program development can have a positive impact on the mental health of clients and increase the capacity of hostels to care for residents with dementia longer.

Despite research evidence that demonstrates the utility of interventions to prevent depression in older adults (e.g., Gallagher et al., 1989; Murphy, 1982; Turner \& Noh, 1988), virtually no preventative work was being done by western Canadian community mental health services for older adults according to MacCourt's (1993) survey. Her survey of 28 community psychogeriatric programs in western Canada revealed that, in spite of their own written mandates, teams reported spending an average of 80 per cent of their time on direct client services leaving only 20 per cent of their time for education of others, research, community development, and community consultation (MacCourt, 1993). There was minimal time spent on health promotion, consultation, education, or community development, all of which might contribute to the early detection or prevention of mental health problems and to their management. Since other work (e.g., preventative work with people with mental health problems rather than mental illness, or providing education to facilities) is not "counted," it is not surprising that programs concentrate their efforts on seeing only the most severely psychiatricallyimpaired persons and "turning them over" quickly. These results appear in stark contrast to the Guidelines (Health and Welfare Canada, 1988a), which state that health promotion, prevention, and early intervention are important program functions. Specific recognition of these activities as legitimate activities of psychogeriatric programs is imperative.

\section{Reducing Health Care Costs}

The second major influence affecting delivery of mental health services to elderly persons is the relatively new and powerful influence of technical rationality on how the needs of older persons with mental health problems are defined, who should provide service, and how services are delivered. Technical rationality is described as

an epistemology of practice derived from positivist philosophy ... it holds that practitioners are instrumental problem-solvers who select the technical means best suited to particular purposes. Rigorous professional practitioners solve well-formed instrumental problems by applying theory and technique derived from systematic, preferably scientific knowledge (Schon, 1987, p.4). 
The continued dominance of the medical paradigm, discussed above, is complemented and reinforced by the current technocratic focus in health care. These perspectives share the authority with "science" and "empirical fact," and place high value on "objectivity" and "hard" tasks as opposed to "relationships," "caring," and "soft" tasks. Chappell (1994) suggests that changes within the delivery of medical care and hospitals are a result of physicians being subordinated to the new breed of corporate managers.

Although technical rationality is purported to be value-neutral and objective, this is arguable. Moody (1987) rejects the very idea of value-free pragmatism which he describes as

value-laden decisions behind a facade of technical criteria (e.g., scales to determine entry to facility) or equally that allows our own values to be buried beneath professional jargon that hides the reality of human choice and responsibility for that choice (p. 13).

Technical rationality deliberately sets about to reduce health care costs. The decisions made to implement this goal are based on values that are foreign to the concept of care but, nevertheless, shape what care will be given and how caring work is done. When cost alone drives what services will be provided to elderly persons with mental health problems, there is no reason to expect that the needs of the psychogeriatric population will be met. Decisions about what services are important or necessary are based on values, and in the current climate monetary value appears primary in directing policy decisions.

Although current health care policy focuses on reducing the use of acute and long-term care beds, (and thus health care costs), there has been virtually no money provided to community services that would support such a transfer (Chappell, 1993). Good community care has been shown to cost at least as much as institutional care (Lamb, 1993). It seems that health care cuts have led to a restriction in services in both the institutional and community sectors, with bigger gaps for people to fall through. Families are being called upon to fill the gaps in care left by constraints in the health care system, whether or not this is appropriate to the resources of the family or to family relationships (Walker, 1991). There is extensive literature on the burden of caregiving, and it has been noted that caring for someone with a dementia is significantly more stressful than caring for someone with a physical illness (Chappell, 1990). Within the current climate, very little support (e.g., emotional or instrumental; education) is provided to family caregivers, as they are not the designated clients.
Havens (1995) contends that there is considerable evidence to show that health care savings can not be found by limiting staffing in community-based longterm care programs. She notes that unreasonably large caseloads inhibit prompt assessment, delay case reviews, mitigate against appropriate and timely reassessments, and preclude innovative solutions. As a result, some clients receive more service than they require, and some less, both costly side-effects of inadequate program staffing (Havens, 1995).

Currently there is an emphasis on outcome measurement that arises within the context of health care reform in general as a means to determine efficiency and effectiveness of services, thereby providing an important balance to analyses of cost alone (Hargreaves, Shumway, Hu, \& Cuffel, 1998; Lyons, Howard, O'Mahoney, \& Lish, 1997). It is quite striking that, when faced with this task, many mental health care providers are unable to articulate program and client goals except in the broadest general terms (e.g., those from the Federal guidelines). Evaluation mechanisms must be designed with an emphasis on goals (e.g., program/system goals: reduced polypharmacy, reduction of unnecessary hospitalization and/or institutionalization; client_focused goals: symptom relief, improved functioning, improved quality of life, reduced stress to caregivers) and not merely reflect how many clients are assessed. Focussing on the goals may promote the use of "best clinical practice" by clarifying the needs, encouraging innovation, and allowing mental health service providers to demonstrate the impact they have within the health care system and on people's lives.

Despite the need, few clinicians have had the knowledge or the allocated time to develop and carry out program evaluations. Poorly designed or implemented outcome evaluations carried out by clinicians or funders can be highly detrimental to programs. However, liaison with health researchers may prove a beneficial partnership in this regard.

\section{Limitations of the Formal Community Care System}

Most of the community-based services used by seniors have not been designed for psychogeriatric clients, and the fit between the needs of the client and the services available is often poor. Services are scarce and psychogeriatric clients must compete for service with those for whom the services were originally designed (e.g., disabled persons without mental health problems). At least in British Columbia, mental health programs for seniors have few services of their own but access home support and facility care through chronic care or long-term care programs. Mental health services (e.g., mental health group homes, sheltered employment, recreation and rehabil- 
itation services) that are available to younger adults with mental health problems are seldom available to those over age 65 . Respite care and long-term facility care, all designed for the frail elderly with chronic health problems, are now used by a frailer, sicker, and older population than a decade ago (Havens, 1995). Many more elderly people with dementia are remaining in the community, often alone and dependant on the community services for their care (Tuokko, MacCourt, \& Heath, 1999; Webber, Fox, \& Burnette, 1994).

With the emergence of many mental health problems in late life comes the need to address housing and residential care issues. Long-term care facilities are poorly designed for a population increasingly experiencing cognitive impairment and, therefore, needing structure, environmental and social cues, and predictability to function at optimum levels (Milke, Dobbe, Rule, \& Milke, 1987). Gutman, MacFadgen, and Killam (1995), in a BC study of problems faced in providing facility care to psychogeriatric clients, identified current direct staffing levels as insufficient in number, and that training was inadequate to address client acuity and behavioural disturbances. Special Care Units (SCU), designed to meet the needs of older persons who wander or have other behavioural problems primarily as a result of moderate to severe dementia, hold the promise that it is possible to successfully modify programs to improve quality of care.

Some mental health clients are not, in practice, eligible for facility care if their behaviour is "aggressive" or "difficult" or if they are seen as potentially difficult for staff to manage or to integrate into the facility (Gutman et al., 1995). Tertiary care beds are being closed or otherwise not available. These clients may remain at home longer than anyone thinks appropriate before a suitable bed becomes available, or they may wait for placement in an expensive acute care bed. Education and support for frontline staff in facilities and the community are imperative if they are to meet the challenges they are likely to encounter in providing care. An adequate number of appropriately-trained staff and environments modified or created to address the special needs of this difficult population must be a priority.

\section{A Comprehensive Service System}

The Guidelines for Comprehensive Services to Elderly Persons With Psychiatric Disorders (Health and Welfare Canada,1988a), carefully describe a collection of guiding principles for planning programs and services for elderly persons with mental health problems in Canada. Key issues are:

- a variety of professionals, community resources, and support personnel are involved;
- community outreach is fundamental, with home assessment of patients and consultation with longterm care facilities;

- $\quad$ a broad framework and multidisciplinary teams are used for assessment, treatment, and planning;

- continuity and co-ordination in service provision are emphasized.

No one discipline can possibly have the breadth of knowledge to understand and address all the mental health needs of elderly people, which we have seen arise from physiological, pharmacological, psychological, and social sources. The knowledge and expertise of a number of disciplines is needed - family physicians, medical specialists such as psychiatrists and geriatricians, occupational therapists, nurses, social workers, and psychologists - with each having specialized knowledge of the older adult and aging in relation to their own discipline. Multi-disciplinary teams using a combination of biological, social, psychological, and environmental approaches with the capacity to provide community out-reach, with inhome assessment and treatment, support for caregivers, and the provision of education to formal and informal caregivers, have come to be seen as key elements in addressing the mental health needs of the elderly people in the community and long-term care facilities (Wargon \& Shulman, 1987; Jones, 1991). Clearly, this ideal practice model is likely to be available only in large centres, and even in this instance the initial information would be gathered by one team member who would call in or consult with people in other disciplines, as needed. In smaller centres it is important that access to pertinent disciplines be available, perhaps through teleconferencing or televideo conferencing when face-to-face consultation is not feasible.

The general aims of mental health care for older persons (Health and Welfare Canada, 1988a) include:

- the reduction of distress to patient and family;

- the improvement and maintenance of function;

- mobilization of the individual's capacity for autonomous living;

- $\quad$ independence should be maximized and maintained at the highest level that can be reached.

Essential roles and functions of specialized psychogeriatric services have been described (Health and Welfare Canada, 1988a) as follows:

- diagnosis of difficult cases which are then referred back to the family physician for treatment;

- development of treatment plans which may involve individual or family psychotherapy, behaviour modification, or a combination of special services, such as physical therapies, electro-convulsive therapy, 
psychotherapy and community outreach, coordination of services;

- $\quad$ assessment relating to legal matters, including determination of competence, advising families of the implication of this determination, and assisting families through the ensuing complexities;

- consultation with community agencies and programs, geriatric and medical_surgical wards of general hospitals and long-term care facilities: this form of consultation focuses on modifying the social milieu by addressing staff attitudes or family dynamics;

- $\quad$ promotion of research, education, and training in the field, including public education on the needs and care of elderly persons with mental health problems.

A central objective of the interventions provided by psychogeriatric care is to keep the person at home, and this may require a mix of public, private, and voluntary services.

An examination of the principles put forward in the Guidelines (Health and Welfare Canada, 1988a) suggests that the field of mental health in older adults emanates from a social model of care and requires the perspectives, knowledge, and expertise of a number of health care professionals in a variety of disciplines. A social model provides a framework for considering all the internal and external factors that contribute to mental health problems, and for interventions that may be medical, psychological, social, or environmental (Novak, 1988). Social models of care tend to be client-centred and incorporate the needs of the client and his/her informal social support network as the legitimate foci of care plans (Havens, 1995). Further, it is understood that the cause of a mental health problem may not reside solely within the client (e.g., depression resulting from social isolation, that in turn results from poverty). Family caregivers provide between 70 and 80 per cent of health care, personal care, and assistance with instrumental tasks for elderly persons in North America (Nahmiash, 1995). However, the presence of an older person requiring care is frequently a source of stress in the family and can particularly affect the primary caregiver. Anxiety, guilt, fatigue, physical illness, restricted social contacts, and depression are often the hallmark of an adult caring for an elderly relative (e.g., Clark, 1987). Assessing the needs of the caregiver and the adequacy of the social supports, facilitating the resolution of difficult feelings related to caregiving, and providing emotional support that enables the caregiver to balance her/his needs with those of the care receiver are all important functions and require the skills of several disciplines. Appropriate care consists of a broad range of indirect interventions, such as consultation with other professionals and agencies; engagement in community development to create or improve sup- port services for clients; preventative work (e.g., groups for clients at risk for depression); advocacy, and education of others. The multi-disciplinary team, rather than individual disciplines operating in isolation, is pivotal to this model.

The social model of care provides a broad, systemic view of mental health problems that goes beyond medical diagnoses to include assessment and management of the impact of the mental problem on the person's social network, relationships, and environment, and vice versa. Physicians or psychiatrists may be involved in the treatment of comorbid medical conditions or psychiatric symptomatology. The diagnosis and treatment of the individual's mental illness is, however, only one facet of his/her care. Any single discipline alone is clearly limited in addressing complex mental health problems.

\section{Summary}

While the federal government has embraced a broad definition of mental health and guidelines for providing psychogeriatric services from a social perspective (Health and Welfare Canada, 1988a,b), the operationalization of these ideals has proven difficult within the present health care climate. Although it has been demonstrated here that elderly people with mental health problems have many needs which are nonmedical in nature, funding for their care both in the community and in facilities is medically driven. The funding comes almost solely from a health care budget where health is operationalized narrowly. The more balanced perspective described in the Guidelines (Health and Welfare Canada, 1988a) is needed. The current range of community services is inadequate and insufficient to meet the needs of older mental health clients, but no money to expand or improve community services seems immediately forthcoming. As stated by the National Advisory Council on Aging, "Health reform means more than controlling costs to achieve an affordable health care system. It means providing appropriate and effective care that is responsive to the changing needs of Canadians" (NACA, 1995b, 20). The mental health needs of older Canadians require careful consideration. Perhaps the present climate of health care reform will provide the impetus necessary for a paradigmatic shift in models of care for this extremely vulnerable segment of our older population.

\section{References}

Badger, T. (1993). Physical health impairment and depression among older adults. IMAGE: Journal of Nursing Scholarship, 25(4), 325-330.

Beland, F. (1997). Editorial: Building Canadian gerontology: a springboard for international recognition? Canadian Journal on Aging, 16(1), 6-10. 
Beresin, E. (1988). Delirium in the elderly. Journal of Geriatric Psychiatry and Neurology, 1(3), 127-143.

Blazer, D., \& Maddox, G. (1982). Using epidemiologic survey data to plan geriatric mental health services. Hospital and Community Psychiatry, 33(1), 42-45.

British Columbia Psychogeriatric Association (1999). Principles of psychogeriatric care. (Available from the British Columbia Psychogeriatric Association, 528 Wentworth Street, Nanaimo, BC, V9R 3E4.)

Butler, R.N. (1975). Psychiatry and the elderly: an overview. American Journal of Psychiatry, 132(9), 893-900.

Butterill, D., O'Hanlon, J., \& Book, H. (1992). When the system is the problem, don't blame the patient: Problems inherent in the interdisciplinary inpatient team. Canadian Journal of Psychiatry, 37(April), 168-172.

Canadian Medical Association. (1987). Health care for the elderly: today's challenges: tomorrow's options. Ottawa, ON: Canadian Medical Association.

Canadian Study of Health and Aging Working Group. (1994). Canadian study of health and aging: study methods and the prevalence of dementia. Canadian Medical Association Journal,150(6): 899-12.

Carstensen, L., \& Fremouw, W. (1981). The demonstration of a behavioural intervention for late life paranoia. Gerontologist, 21(3): 329-333.

Chadwick, P. \& Lowe, C. (1994). A cognitive approach to measuring and modifying delusions. Behav. Re. Ther., 32(3): 355-367.

Chappell, N. (1990). Aging and social care. Handbook of Aging and the Social Sciences, Third edition. (pp. 438-454). Academic Press, Inc.

Chappell, N. (1993). The future of health care in Canada. Journal of Social Polocy, 22(4), 487-505.

Chappell, N. (1994). Home care research: what does it tell us? The Gerontologist, 34(1), 116-120.

Clark, D. (1987). In Wasylenki et al. (Eds.), Psychogeriatrics: a practical handbook. Toronto: Gage Educational Publishing Co.

Clark, W., \& Vorst, V. (1994). Group therapy with chronically depressed geriatric patients. Journal of Psychosocial Nursing, 32(5), 9-13.

Gallagher, D., Rose, J., Rivera, P., et al. (1989). Prevalence of depression in family caregivers. Gerontologist, 29(4), 449-456.

German, P., Shapiro, B., \& Skinner, E. (1985). Mental health of the elderly: use of health and mental health services. Journal of the American Geriatrics Society, 33(4), 246-252.

Gurland, B.J., \& Cross, P.S. (1982). Epidemiology of psychopathology in old age: some implications of clinical services. Psychiatric Clinics of North America, 5(1), 11-26.

Gutman, G., MacFadgen, L., \& Killam, J. (1995). Psychogeriatric client identification project. Burnaby: Simon Fraser University

Hargreaves, W.A., Shumway, M., Hu, T., \& Cuffel, B. (1998). Cost-outcome methods for mental health. San Diego: Academic Press.

Havens, B. (1995). Long-term care diversity within the care continuum. Canadian Journal on Aging, 14(2), 245-263.
Health and Welfare Canada. (1988a). Guidelines for comprehensive services to elderly persons with psychiatric disorders. Ottawa, ON: Supply and Services Canada.

Health and Welfare Canada (1988b). Mental health for Canadians: Striking a balance. Ottawa ON: Supply and Services Canada.

Health and Welfare Canada (1990). Services to elderly residents with mental health problems in long-term care facilities: guidelines. Ottawa, ON: Supply and Services Canada.

Health and Welfare Canada. (1991). Mental health problems among Canada's seniors: demographic and epidemiologic considerations. Ottawa, ON: Supply and Services.

Janicki, M., \& Dalton, A.J. (1999). Dementia, aging and intellectual abilities: A handbook. Philadelphia: Brunner/Mazel, Inc.

Jeste, D., Harris, M., \& Paulsen, J. (1996). Psychoses. In Sadavoy, J., Lazarus, L, Jarvik, L., Grossberg, G. (Eds.), Comprehensive review of geriatric psychiatry-II. (pp. 593-614). Washington, DC: American Psychiatric Press.

Jones, R. (1991). Community service in old age psychiatry. Current Opinion in Psychiatry, 4, 603-607.

Kenny, N. (1996). Presented at the Canadian Bioethics Society Conference, Montreal.

Knight, B. (1994). Home-delivered mental health services: An idea whose time has come? Gerontologist, 34(2), 149.

Knight, B.G., \& Kaskie, B. (1995). Models of mental health service delivery to older adults. In M. Gatz (Ed.), Emerging issues in mental health and aging (pp. 231-255). Washington, DC: American Psychological Association.

Lamb, R. (1993). Lessons learned from deinstitutionalization in the U.S. British Journal of Psychiatry, 162, 587-592.

Lebowitz, B.D. (1988). Correlates of success in community mental health programs for the elderly. Hospital and Community Society, 39(7), 721-722.

Lee, M. (1996). Drugs and the elderly: do you know the risks? American Journal of Nursing, 96(7), 25-31.

Lipowski, Z.J. (1989). Delirium in the elderly patient. New England Journal of Medicine, 320(9), 378-381.

Lyons, J.S., Howard, K.I., O'Mahoney, M.T., \& Lish, J.D. (1997). The measurement and management of clinical outcomes in mental health. New York: John Wiley \& Sons, Inc.

Macaskill, N. (1987). Delusional parasitosis: Successful nonpharmacological treatment of a folie-a-deux. British Journal of Psychiatry, 150: 261-263.

MacCourt, P. (1993). A survey of community psychogeriatric outreach programs in western Canada. Unpublished Master's thesis, University of Manitoba, Winnipeg, Manitoba.

Martin, B. (1987). In Wasylenki et al. (Eds.), Psychogeriatrics: a practical handbook, Toronto: Gage Educational Publishing Co.

McCubbin, M. (1994). Deinstitutionalization: The illusion of disillusion. The Journal of Mind and Behavior, 15(1,2), 3554.

McCullough, P. (1991). Geriatric depression: atypical presentations, hidden meanings. Geriatrics, 46(10), 72-76. 
Milke, D., Dobbe, A., Rule, B., \& Milke, A. (1987). The activities of Alzheimer patients and non-demented residents of a nursing home. Paper presented at the annual meeting of the Canadian Psychological Association, Vancouver, BC.

Ministry of Health and Ministry Responsible for Seniors, (1996). Policy framework for seniors with mental health problems (draft). Province of BC.(September).

Mittelman, M., Ferris, S., Steinberg, G., Shulman, E., Mackell,J., Ambinder, A., \& Cohen, J. (1993). An intervention that delays institutionalization of Alzheimer's disease patients: Treatment of spouse-caregivers. Gerontologist, 33(6): 730-740.

Moody, H. (1987). Ethical dilemmas in nursing home placement. Generations. Summer, 16-23.

Mossey, J., Knott, K., Higgins, M., \& Talerico, K. (1996). Effectiveness of a psychosocial intervention, interpersonal counselling for subdysthymic depression in medically ill elderly. Journal of Gerontology, 51A(4), M172176.

Murphy, E. (1982). Social origins of depression in old age. British Journal of Psychiatry, 141, 135-142.

Nahmiash, D. (1995). Informal caregiving: women's care or work? In Sawyer, E. \& Stephenson, M. (Eds.), Continuing the care: the issues and challenges of long-term care (pp. 247-269). Ottawa, ON: CHA Press.

National Advisory Council on Aging (NACA) (1995). The NACA position on community services in health care for seniors: Progress and challenges. Ottawa: NACA.

Novak, M. (1988). Aging and society, Nelson

Paterson, R.D. (1976). Services for the aged in community mental health centres. American Journal of Psychiatry, 133(3), 271-273.

Pearson, J., \& Conwell, Y. (1995). Suicide in late life: challenges and opportunities for research. International Psychogeriatrics, 7, 131-135.

Rockwell, E., Jackson, E., \& Vilke, G. (1994). A study of delusions in a large cohort of Alzheimer disease patients. American Journal of Geriatric Psychiatry, 2, 157-164.

Rosewarne, R., Bruce, A., McKenna, M. (1997). Dementia programme effectiveness in long-term care. International Journal of Geriatric Psychiatry, 12: 173-182.
Schon, D. (1987). Educating the reflective practioner. San Francisco: Jossey-Bass.

Scogin, F., \& McElreath, L. (1994). Efficacy of psychosocial treatments for geriatric depression: A quantitative review. Journal of Consulting and Clinical Psychology, 62(1), 69-73.

Shulman, R. (1991). Regionalization of psychiatric services for the elderly. Canadian Journal of Psychiatry, 36, 3-8.

Spar, J., \& LaRue, A. (1990). Concise guide to geriatric psychiatry. Washington: American Psychiatric Press, Inc.

Statistics Canada (1990). The health and activity limitation survey: highlights- disabled persons. (Catalogue 83-603). Ottawa: Supply and Services.

Stolee, P., LeClair, K., \& Kessler, L. (1994). Geriatric psychiatry consultation in the community. Canadian Journal of Psychiatry, 39 (October), S27-S33.

Tuokko, H., Frerichs, R., Halpern, S., \& Eisner, M. (1999). Delusional symptomatology as seen by a community outreach team. Aging and Mental Health, 3(2), 136_142.

Tuokko, H., MacCourt, P., \& Heath, Y. (1999). Home alone with dementia. Aging and Mental Health, 3(1), 21-27.

Turner, R., \& Noh, S. (1988). Physical disability and depression. Journal of Health and Social Behaviour, 29, 23-27.

Walker, A. (1991). The relationship between the state and the family in the care of older people. Canadian Journal on Aging, 10(2), 94-112.

Wargon, M., \& Shulman, K. (1987). Community psychiatric services for the elderly: the Sunnybrook experience. Canada's Mental Health, March, 3-6.

Wasylenki, D., Martin, B., Lennox, E., Perry, L., \& Harrison, M. (1987). Psychogeriatrics: a practical handbook, Toronto: Gage Educational Publishing Co.

Webber, P., Fox, P., \& Burnette, D. (1994). Living alone with Alzheimer's disease: effects on health and social service utilization patterns. The Gerontologist, 34(1), 8-14.

World Health Organization \& World Psychiatric Association (1998).Organization of care in psychiatry of the elderly: a technical consensus statement. Aging and Mental Health, 2(3): 246-252.

Zarit, S.H. (1980). Aging and mental disorders: Psychological approaches to assessment and treatment. New York: New York Free Press.

This position paper was prepared by Penny MacCourt, M.S.W., Holly Tuokko, Ph.D., and Mary Tierney, Ph.D., at the request of the Canadian Association on Gerontology. It was approved by the Board as an official policy statement of the CAG on November $28,2000$. 